Angela D. Thomason • Janis M. Miller •

John OL DeLancey

\title{
Urinary incontinence symptoms during and after pregnancy in continent and incontinent primiparas
}

Received: 13 January 2006 / Accepted: 17 March 2006

(C) International Urogynecology Journal 2006

\begin{abstract}
Objective: Examine patterns of urinary incontinence during and after pregnancy, as recalled by incontinent and continent primiparas. Study design: Primiparous women reporting no pre-pregnancy incontinence, were recruited 6 to 9 months postpartum. Those reporting current continence and demonstrating a negative stress test were considered "Primiparous Continent" (PC, $n=64)$. Those reporting current incontinence and demonstrating a positive stress test were considered "Primiparous Incontinent" (PI, $n=57)$. Subjects self-administered a questionnaire recalling leakage during and after pregnancy. Results: Sixteen percent of PC women leaked during pregnancy. Of these, $70 \%$ experienced frequent leakage during pregnancy. Seventy-eight percent of PI women leaked both during and after pregnancy. Several patterns arose surrounding leakage frequency for PI women: $19 \%$ only leaked frequently during pregnancy, $4 \%$ only leaked frequently after pregnancy, and $51 \%$ leaked frequently both during and after pregnancy. Conclusion: Nearly five times as many primiparous incontinent women, compared with primiparous continent women, leaked during pregnancy.
\end{abstract}

Keywords Pregnancy $\cdot$ Urinary incontinence $\cdot$ Postpartum incontinence

A. D. Thomason · J. M. Miller · J. O. DeLancey

Division of Gynecology, Department of Obstetrics and Gynecology, University of Michigan Medical School,

Ann Arbor, MI, USA

J. M. Miller

School of Nursing, University of Michigan,

Ann Arbor, MI, USA

A. D. Thomason $(\bowtie)$

L4000 Women's Hospital,

1500 East Medical Center Drive,

P.O. Box 0276, Ann Arbor, MI 48109-0276, USA

e-mail: adt@med.umich.edu

Tel.: +1-734-7648429

Fax: +1-734-6479727

\section{Introduction}

Many women report urinary incontinence during pregnancy or after childbirth. For some women, this incontinence resolves with postpartum healing, but for others it becomes long-lasting. This study was aimed to examine incontinent and continent primiparas' recall of continence status during and after pregnancy. The study focuses on the presence and frequency of urinary incontinence to reveal patterns of leakage and distinguish time courses of urinary incontinence onset.

\section{Materials and methods}

This study is part of a parent project investigating vaginal delivery and stress urinary incontinence at the University of Michigan. Primiparous women who had one term vaginal delivery (spontaneous or operative) and reported no prepregnancy incontinence were recruited between 6 and 9 months postpartum for an IRB-approved study of postpartum stress incontinence. At screening, women were excluded if they had genital anomalies, had conditions such as diabetes that might pose increased risk of urinary tract infection, had prior urinary tract surgery, were currently pregnant, delivered by cesarean section, or reported symptoms of urinary incontinence before pregnancy. Those who were eligible gave informed consent. Each woman's bladder was filled with $250 \mathrm{ml}$ of normal saline to perform a standing cough stress test [1]. During the stress test, each woman held a paper towel at the perineum and was asked to cough hard three times. Women who leaked any amount of urine were considered to have a positive stress test, and those who did not leak were considered as having a negative stress test. Each woman was asked at the time of enrollment if she was currently experiencing any urine leakage and was also asked if she experienced any urinary incontinence before pregnancy. Primiparous women who reported no incontinence symptoms at enrollment and had a negative stress test at the time of testing, were assigned to the "Primiparous Continent" 
group (PC, $n=80$ ). Primiparous women who reported symptoms of incontinence at enrollment and who had a positive stress test were assigned to the "Primiparous Incontinent" group (PI, $n=80)$. Women who reported no incontinence symptoms at enrollment, but had a positive stress test were not included in the study. Likewise, women who reported current incontinence symptoms at enrollment, but had a negative stress test were excluded. These sample sizes were based on a power calculation conducted for the parent study. Demographic information including age, race, height, weight, and birth weight were collected for each subject.

Each subject completed a 64-item, self-administered questionnaire concerning recall of continence from 35 weeks until delivery (during pregnancy) and at 6 months postpartum (after pregnancy). As part of the questionnaire, each subject answered two questions concerning the frequency of their incontinence at these two time points. The first question corresponded to "any leakage": "Have you involuntarily lost or leaked any amount of urine?" The second question corresponded to "frequent leakage": "Have you involuntarily lost or leaked any amount of urine at least a few times per week?" Each subject responded "Yes" or "No" for each of the time periods. Subjects reporting leakage at least a few times per week were considered as having "frequent" leakage, and those who leaked less than a few times per week were considered as having "infrequent" leakage. For this analysis, subjects
Table 1 Demographic comparisons of age, BMI, birth weight, and race

\begin{tabular}{lrrr}
\hline & PC $(n=64)$ & PI $(n=57)$ & $p$ value \\
\hline Mean age (years) & 29.7 & 29.8 & 0.9146 \\
Mean BMI & 23.0 & 26.9 & 0.0001 \\
Mean birth weight (grams) & $3,392.6$ & $3,560.4$ & 0.0647 \\
White (percent) & 87.5 & 89.5 & 0.2860 \\
African-American (percent) & 9.4 & 3.5 & \\
Other (percent) & 3.1 & 7.0 & \\
\hline
\end{tabular}

were excluded if their questionnaires were missing (PC, $n=9 ; \mathrm{PI}, n=5)$ or their questionnaire responses were inconsistent with their enrollment reports of current leakage and/or leakage before pregnancy (PC, $n=7$; PI, $n=17$ ). Subjects were included if some, but not all questions were answered. The PC group had a final sample size of $n=64$ and the PI group had a final sample size of $n=57$. The response rates for each time period and the response pattern for each subject were analyzed. Subgroups were developed based on response patterns.

\section{Results}

Table 1 shows that the PC and PI groups did not differ significantly in age, birth weight, and race. The PI group

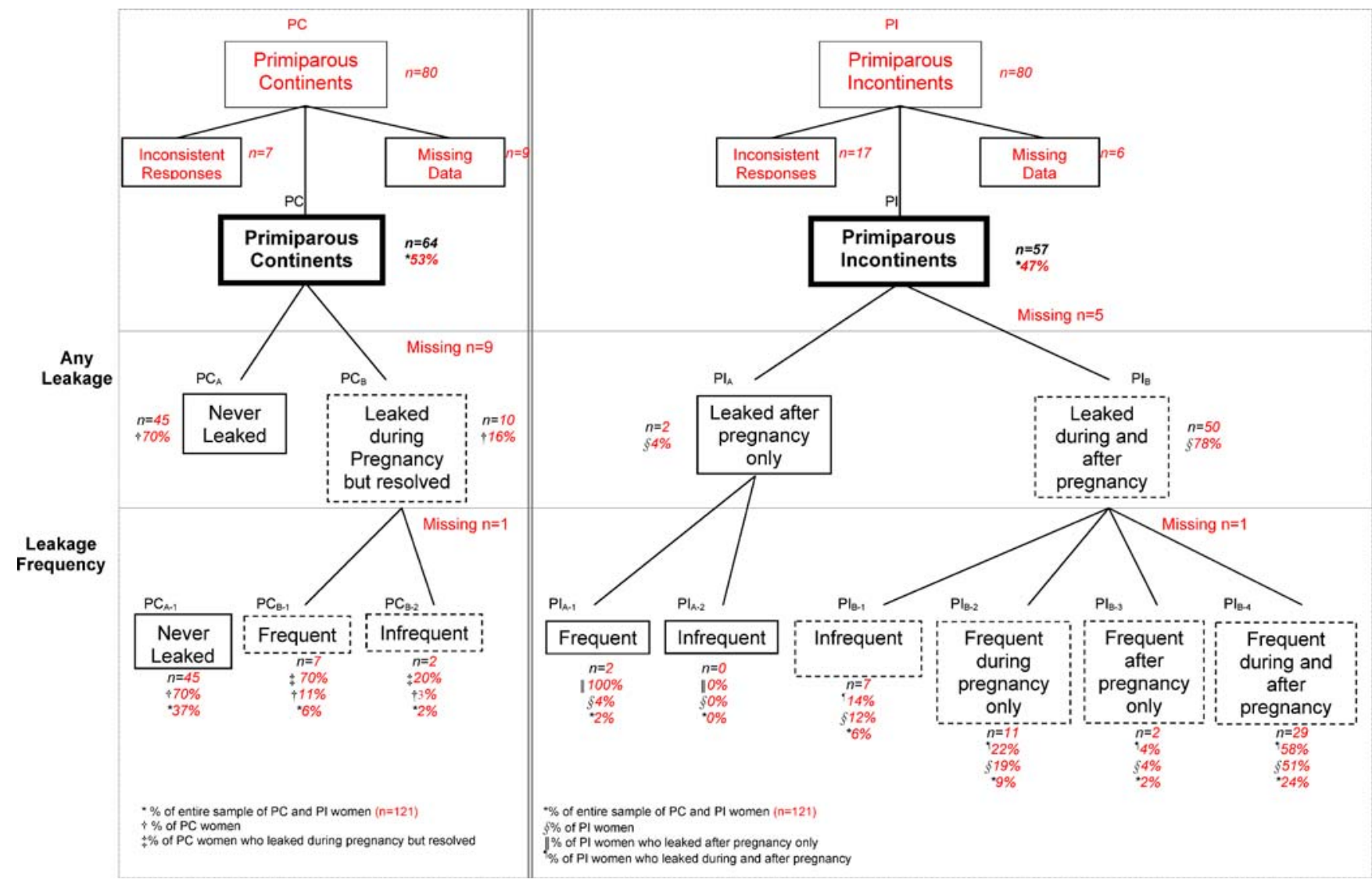

Fig. 1 The occurrence and frequency of leakage in primiparous continent and incontinent women at different time points 
had significantly higher BMI than the PC group. Fig. 1 shows the breakdown of symptoms during and after pregnancy for the two groups, PC and PI. The amounts of leakage are listed in two tiers below these groups: the first tier shows results of the question that asked about any leakage ("any leakage") and the second tier displays further breakdown based on information obtained from the question concerning frequent leakage ("leakage frequency"). Overall, $37 \%$ of the entire sample never leaked, $8 \%$ of the entire sample had leakage during pregnancy that resolved, and $47 \%$ of the entire sample had leakage that had not resolved at 6 months postpartum. The PI group had a significantly higher report of urine leakage during pregnancy than the $\mathrm{PC}$ group ( $\mathrm{PI}=78 \%, \mathrm{PC}=16 \% ; p<0001)$.

In the $\mathrm{PC}$ group, $16 \%$ reported leakage during pregnancy $\left(\mathrm{PC}_{\mathrm{B}}\right)$; of these, $70 \%$ leaked frequently $\left(\mathrm{PC}_{\mathrm{B}-1}\right)$. When considering the entire sample of $\mathrm{PC}$ women, approximately one-tenth reported frequent leakage during pregnancy $\left(\mathrm{PC}_{\mathrm{B}-1}\right)$. Among the PI women, $78 \%$ reported leakage during pregnancy $\left(\mathrm{PI}_{\mathrm{B}}\right)$. Of these, $58 \%$ leaked frequently during pregnancy $\left(\mathrm{PI}_{\mathrm{B}-2}+\mathrm{PI}_{\mathrm{B}-4}\right)$. Over one-half $(58 \%)$ experienced frequent rates both during and after pregnancy $\left(\mathrm{PI}_{\mathrm{B}-4}\right)$, an additional $4 \%$ experienced frequent rates only after pregnancy $\left(\mathrm{PI}_{\mathrm{B}-3}\right)$, while the remaining women either experienced infrequent leakage $\left(14 \% ; \mathrm{PI}_{\mathrm{B}-1}\right)$, or only did so during pregnancy $\left(22 \%\right.$; $\left.\mathrm{PI}_{\mathrm{B}-2}\right)$. Considering the entire PI group (including those who leaked during pregnancy and after pregnancy, as well as those who only leaked after delivery), $12 \%$ reported that the leakage was never frequent $\left(\mathrm{PI}_{\mathrm{A}-2}+\mathrm{PI}_{\mathrm{B}-1}\right)$. However, the most common pattern of frequent leakage experience among the PI group was frequent leakage that occurred both during and after pregnancy $\left(\mathrm{PI}_{\mathrm{B}-4}\right)$.

Overall, the majority (51\%) of the entire sample of PC and PI women experienced some urine leakage at one or more of the two time points $\left(\mathrm{PC}_{\mathrm{B}}+\mathrm{PI}_{\mathrm{A}}+\mathrm{PI}_{\mathrm{B}}\right) ; 42 \%$ of the entire sample experienced frequent urine leakage at one or more of the two time points $\left(\mathrm{PC}_{\mathrm{B}-1}+\mathrm{PI}_{\mathrm{A}-1}+\mathrm{PI}_{\mathrm{B}-2}+\mathrm{PI}_{\mathrm{B}-3}+\mathrm{PI}_{\mathrm{B}-4}\right)$. For those women in whom leakage occurred during pregnancy $\left(\mathrm{PC}_{\mathrm{B}}+\mathrm{PI}_{\mathrm{B}} ; n=60\right)$, leakage resolved postpartum for some $\left(\mathrm{PC}_{\mathrm{B}} ; n=10\right)$. Of the women who reported "frequent" leakage during pregnancy $\left(\mathrm{PC}_{\mathrm{B}-1}+\mathrm{PI}_{\mathrm{B}-2}+\mathrm{PI}_{\mathrm{B}-4} ; n=47\right), 51 \%$ continued to leak frequently after delivery $\left(\mathrm{PI}_{\mathrm{B}-4} ; n=29\right)$.

\section{Discussion}

Primiparous incontinent women had a higher self-reported rate of urinary incontinence symptoms during pregnancy than primiparous continent women. Prevalence and incidence rates of urinary incontinence during and after pregnancy reveal that there are several patterns of incontinence onset surrounding pregnancy and delivery. This study aimed to look at the patterns by distinguishing time courses of urinary incontinence onset. Distinguishing time courses of urinary incontinence onset provides insight into the differences between transient incontinence due to the hormonal and mechanical effects of pregnancy and damage that occurs as a result of vaginal birth. Previous studies have distinguished time courses of urinary incontinence onset before, during, and after pregnancy [2-5] as well as during and after pregnancy only [6-11]. However, most of these studies included women of varying parity $[5-7,9$, 11], or assessed short-term postpartum incontinence at less than 6 months postpartum that might likely resolve $[4,6,9$, 11-13]. Prevalence estimates of incontinence studies within a population of women less than 6 months postpartum likely include some women whose symptoms will spontaneously resolve as part of the postpartum healing process, thus resulting in an overestimate of incontinence prevalence. The inclusion of only primiparous women in this study allowed for the effects of one vaginal delivery to be more distinguishable and eliminated the possible confounding and cumulative effects of multiple deliveries that may have occurred in other studies. In addition, determining the prevalence of urinary incontinence at least 6 months postpartum allows for any spontaneous recovery from transient incontinence during pregnancy and immediately after delivery to occur, thereby focusing on more long-term incontinence.

Prevalence rates for incontinence during pregnancy are reported in the literature ranging from 20 to $62 \%[2-4,6,7$, $12,13]$. The finding that nearly half of the women in this study reported leakage during pregnancy is consistent with these rates. Onset of symptoms after delivery reported in this study $(2 \%)$ is inconsistent with other incidence rates of urinary incontinence after childbirth ranging from 7 to $19 \%$ $[2,3,14]$. These findings are also inconsistent with the increased occurrence of stress incontinence observed in women who have delivered vaginally compared to others in the population [15] and do not support the hypothesis of vaginal delivery as the predominant risk factor for these women. The observations in this study show multiple patterns contributing to the onset of urinary incontinence symptoms during and after pregnancy. Vaginal birth alone cannot account for the high rate of new onset incontinence in pregnancy. The most common experience of continent women at 6 months postpartum was never experiencing leakage at all, yet one-sixth of these women experienced leakage in pregnancy.

Causes of gestational incontinence are unclear. Hormonal effects during pregnancy, including effects of the reproductive hormone relaxin [16], increased hormonal concentrations, and local tissue changes caused by hormones [3] may affect the continence mechanism during pregnancy. Variability in strength and thickness of pelvic floor muscle function in pregnant incontinent women may also influence the continence mechanism during pregnancy [17]. Pregnancy-related changes may also influence postpartum incontinence. These changes include substantial bladder neck mobility [10], diminished functional urethral length [18], damage to the urethra and its suspension [19], decreased maximum urethral closure pressures $[10,16$, 18], and lower intra-vaginal and intra-anal pressures during pregnancy both at rest $[18,19]$ and during pelvic muscle contractions [10].

Postpartum incontinence may also be caused by changes in the pelvic floor. These changes include anterior vaginal 
descent [20], anal sphincter damage [21], displacement of the urethro-vesical junction [22], greater bladder neck mobility [23], and increased pudendal nerve terminal motor latency $[24,25]$. The occurrence of these changes may be the result of vaginal delivery alone, but may also be affected by other obstetric variables such as operative vaginal delivery [4, 14, 26, 27], episiotomy [2], long second stage of labor [2], and infant birth weight $[2,28]$. Some studies, however, were not able to find significant obstetric relationships $[13,29,30]$.

The cross-sectional design of this study limits the ability to determine cause and effect, thus predictive mechanistic hypotheses cannot be tested. Predictive testing would ideally require a longitudinal study design that follows women from the pre-pregnancy state to the 6-month postpartum state or longer. The study design also involved the use of recall with accompanying potential bias. If this bias had existed, those who were incontinent may have been more likely to recall occurrence of incontinence during pregnancy, resulting in an overestimate of pregnancy-related incontinence prevalence. Likewise, those who were continent may have been less likely to recall incontinence occurrence during the pregnancy, resulting in an underestimate of pregnancy-related incontinence prevalence. This study excluded women with inconsistent questionnaire responses and stress test results. Women in the PC group with inconsistent responses and positive stress tests may have had urine leakage during pregnancy, thereby resulting in an underestimate of urine leakage during pregnancy in the PC group. Likewise, women in the PI group with inconsistent responses and negative stress tests may not have had urine leakage during pregnancy, thereby resulting in an overestimate of urine leakage during pregnancy in the PI group.

Results from this study are thought-provoking and indicate the need for measuring incidence as well as prevalence. The results also indicate a need for examining frequency of leakage as well as any leakage, to test predictive and mechanistic hypotheses. Studies that build upon these insights and seek to explore the proposed hypotheses will contribute significantly to the advancement in the understanding, prevention, and treatment of urinary incontinence.

Acknowledgements We gratefully acknowledge support from National Institutes of Heath/National Institute of Diabetes \& Digestive \& Kidney Diseases grant R01 DK 51405.

\section{References}

1. Miller J, Ashton-Miller J, DeLancey J (1998) Quantification of cough-related urine loss using the paper towel test. Obstet Gynecol 91(5):705-709

2. Viktrup L, Lose G, Rolff M, Barfoed K (1992) The symptom of stress incontinence caused by pregnancy or delivery in primiparas. Obstet Gynecol 79(6):945-949

3. Hvidman L, Hvidman L, Foldspang A, Mommsen S, Nielsen JB (2002) Correlates of urinary incontinence in pregnancy. Int Urogynecol J Pelvic Floor Dysfunct 13(5):278-283
4. Dolan LM, Walsh D, Hamilton S, Marshall K, Thompson K, Ashe RG (2004) A study of quality of life in primigravidae with urinary incontinence. Int Urogynecol J Pelvic Floor Dysfunct 15(3):160-164

5. Hvidman L, Foldspang A, Mommsen S, Nielsen JB (2003) Postpartum urinary incontinence. Acta Obstet Gynecol Scand 2(6):556-563

6. Morkved S, Bo K (1999) Prevalence of urinary incontinence during pregnancy and postpartum. Int Urogynecol J Pelvic Floor Dysfunct 10(6):394-398

7. Wijma J, Weis Potters AE, de Wolf BT, Tinga DJ, Aarnoudse JG (2001) Anatomical and functional changes in the lower urinary tract during pregnancy. BJOG 108(7):726-732

8. Dolan LM, Hosker GL, Mallett VT, Allen RE, Smith AR (2003) Stress incontinence and pelvic floor neurophysiology 15 years after the first delivery. BJOG 110(12):1107-1114

9. Thorp JM Jr, Norton PA, Wall LL, Kuller JA, Eucker B, Wells E (1999) Urinary incontinence in pregnancy and the puerperium: a prospective study. Am J Obstet Gynecol 181(2):266-273

10. Meyer S, Schreyer A, De Grandi P, Hohlfeld P (1998) The effects of birth on urinary continence mechanisms and other pelvic-floor characteristics. Obstet Gynecol 92(4 Pt 1):613-618

11. Chiarelli P, Campbell E (1997) Incontinence during pregnancy. Prevalence and opportunities for continence promotion. Aust N Z J Obstet Gynaecol 37(1):66-73

12. Chaliha C, Kalia V, Stanton SL, Monga A, Sultan AH (1999) Antenatal prediction of postpartum urinary and fecal incontinence. Obstet Gynecol 94(5 Pt 1):689-694

13. Mason L, Glenn S, Walton I, Appleton C (1999) The prevalence of stress incontinence during pregnancy and following delivery. Midwifery 15(2):120-128

14. Viktrup L (2002) The risk of lower urinary tract symptoms five years after the first delivery. Neurourol Urodyn 21(1):2-29

15. Rortveit G, Daltveit AK, Hannestad YS, Hunskaar S (2003) Urinary incontinence after vaginal delivery or cesarean section; Norwegian EPINCONT Study. N Engl J Med 348(10):900-907

16. Kristiansson P, Samuelsson E, von Schoultz B, Svardsudd K (2001) Reproductive hormones and stress urinary incontinence in pregnancy. Acta Obstet Gynecol Scand 80(12):1125-1130

17. Morkved S, Salvesen KA, Bo K, Eik-Nes S (2004) Pelvic floor muscle strength and thickness in continent and incontinent nulliparous pregnant women. Int Urogynecol J Pelvic Floor Dysfunct

18. Iosif S, Ulmsten U (1981) Comparative urodynamic studies of continent and stress incontinent women in pregnancy and in the puerperium. Am J Obstet Gynecol 140(6):645-650

19. Iosif S, Henriksson L, Ulmsten U (1981) Postpartum incontinence. Urol Int 36(1):53-58

20. Dietz HP, Clarke B, Vancaillie TG (2002) Vaginal childbirth and bladder neck mobility. Aust NZ J Obstet Gynaecol 42(5):522-525

21. Tetzschner T, Sorensen M, Lose G, Christiansen J (1996) Anal and urinary incontinence in women with obstetric anal sphincter rupture. Br J Obstet Gynaecol 103(10):1034-1040

22. Sartori JP, Sartori MG, Baracat EC, DeLima GR, Girao MJ (2004) Bladder neck mobility and functional evaluation of the pelvic floor in primiparae according to the type of delivery. Clin Exp Obstet Gynecol 31(2):120-122

23. Meyer S, De Grandi P, Schreyer A, Caccia G (1996) The assessment of bladder neck position and mobility in continent nullipara, mulitpara, forceps-delivered and incontinent women using perineal ultrasound: a future office procedure? Int Urogynecol J Pelvic Floor Dysfunct 7(3):138-146

24. Tetzschner T, Sorensen M, Jonsson L, Lose G, Christiansen J (1997) Delivery and pudendal nerve function. Acta Obstet Gynecol Scand 76(4):324-331

25. Snooks SJ, Swash M, Henry MM, Setchell M (1986) Risk factors in childbirth causing damage to the pelvic floor innervation. Int J Colorectal Dis 1(1):20-24

26. Van Kessel K, Reed S, Newton K, Meier A, Lentz G (2001) The second stage of labor and stress urinary incontinence. Am J Obstet Gynecol 184(7):1571-1575 
27. Burgio KL, Zyczynski H, Locher JL, Richter HE, Redden DT, Wright KC (2003) Urinary incontinence in the 12-month postpartum period. Obstet Gynecol 102(6):1291-1298

28. Rortveit G, Daltveit AK, Hannestad YS, Hunskaar S (2003) Vaginal delivery parameters and urinary incontinence: the Norwegian EPINCONT study. Am J Obstet Gynecol 189(5):1268-1274
29. Meyer S, Hohlfeld P, Achtari C, Russolo A, De Grandi P (2000) Birth trauma: short and long term effects of forceps delivery compared with spontaneous delivery on various pelvic floor parameters. BJOG 07(11):1360-1365

30. Peschers UM, Sultan AH, Jundt K, Mayer A, Drinovac V, Dimpfl T (2003) Urinary and anal incontinence after vacuum delivery. Eur J Obstet Gynecol Reprod Biol 110(1):39-42 